\title{
Direct Calculation and Evaluation of Structure Strength for Offshore Wind Power Operation and Maintenance Catamaran
}

\author{
Chao Chen" and Zhi Liu \\ School of Mechanical Engineering, Jiangsu University of Science and Technology, Zhenjiang 212003, China \\ ${ }^{*}$ Corresponding author
}

\begin{abstract}
A wind power operation and maintenance ship is one kind of the important equipment to maintain the offshore wind farms. In this paper, the whole structure of operation and maintenance of catamaran is introduced firstly, finite element model of the catamaran and a hydrodynamic calculation model are established, and the whole ship wave load is forecasted subsequently. Considering to the different sea conditions, entering or leaving harbor, full or no load and wave directions, are divided into 7 calculation conditions. The design wave method is used to calculate the wave load of the wind power operation and maintenance ships under various work conditions. Also considering the lateral force and anti-symmetric vertical uniform force under different work conditions, the stress of the entire ship finite element model including wave pressure application and the inertial force application is analyzed subsequently in this paper. According to the relevant requirements of the "domestic sailing ships manufacturing specification", structure strength of the wind power operation and maintenance catamaran is checked and the total strength is evaluated by direct calculation method. The analysis results show that the direct calculation and evaluation is very effective in analyzing the ship structure strength of the wind power operation and maintenance ships, and the effective optimization and improvement reference for the design and development of the kind of ships can be provided from the evaluation results.
\end{abstract}

Keywords-offshore wind power operation and maintenance catamaran; finite element analysis; wave pressure; design wave method; direct calculation and evaluation

\section{INTRODUCTION}

Wind power is a kind of stable clean and renewable energy. And more attention is paid to this energy coupled with the increasingly worsening environment pollution and deteriorating greenhouse effect. Compared to the onshore wind farm, the offshore wind farm has some superiority, such as stronger speed, more stable direction of wind and so on. Therefore, focusing more on wind-generated electricity, many countries have begun to establish the offshore wind farm. There is a huge promoting effect for the large-scale development of offshore wind power with enhancement of technology and the decline of development cost, So offshore wind power will be developed and utilized more widely and deeply ${ }^{[1]}$.

In some European and American countries, the offshore wind power has been developed a lot. In the meantime, many wind power operation and maintenance ship types have been formed with the growing of research and design. There are many foreign companies leading the field of wind power operation and maintenance ship, including BMT Nigel Gee, South Boasts IOW, Damen Shipyards, Incat Crowther in Australia, Austal, etc. Compared to those, the research and design of China's wind power operation and maintenance ship are developed rapidly in recent years, although the previous comparison is lagging behind. Traditional operation and maintenance catamaran are designed and three improving schemes based on wave piercing hull line's modified catamaran and small water-plane-area twin hull line's modified catamaran are put forward by Zhang Xiuping ${ }^{[2]}$. One type of finite element model of wind power operation and maintenance catamaran is analyzed by Wei $\mathrm{Li}^{[3]}$ and the framework of cross structure is also optimized. The wind power operation and maintenance ship is carried on multi-disciplinary design optimization by Yao Zhuangle ${ }^{[4]}$, which is divided into resistance, structure and seakeeping quality three sub disciplines and the corresponding approximate model is established. Through studying the impact of different demihull separation of catamaran on resistance by CFD simulation, Yang Lingyu ${ }^{[5]}$ got a more appropriate spacing. In November 2014, "Longyuan operation No.1", the wind power operation and maintenance ship, designed by China Ship Scientific Research Center (CSSRC), has been verified for acceptance and put into operation. Designed for the offshore wind farm in Donghai Bridge, "Donghai Wind Power No.1", the wind power operation and maintenance ship was come into service in June 2015, which is the first domestic special marine working ship ${ }^{[6]}$ combining with transportation and maintenance about offshore wind turbines.

Currently, wind power operation and maintenance ship can be divided into catamaran and trimaran. The former with advantages of large deck area, spacious layout, good stability, higher speed, better seakeeping and so on, can ensure the safety of offshore operators and satisfy the demand of maintenance and development for offshore wind power farm. For offshore wind power farm's daily inspection, maintenance, marine traffic and so on, a new design method of operation and maintenance catamaran was proposed in this paper. The coastal navigation is deemed a designed navigation. Firstly, according to working condition, main parameters and other factors of operation and maintenance ship, the overall structure and layout are designed and the finite element model of whole ship is set up. The finite element model is calculated under different working conditions and design wave conditions. Analyzing 
wave stress, checking or evaluating strength are carried out subsequently.

\section{The Overall Structure Design of Wind Power OPERATION AND MAINTENANCE CATAMARAN}

Offshore wind power operation and maintenance ship is mainly used for daily inspection, maintenance, marine traffic and so on. So owning complete functional facilities and providing a comfortable and convenient working environment for passengers and crew is required. In this paper, the designed hull of operation and maintenance ship is called as catamaran workboat, which owns double engines, sculls and rudders. The two demihulls of ship's body are connected by a torsional box and a cross structure, and equipped with a spacious deck. Between the port side and starboard's steel fender, rear outboard corner, extrusive interrupted rubber fenders are set in order to protect the ship efficiently when impact happened or calling at wind power port.

The main performance is required as follows. The main engine power is one hundred percent M.C.R at full load design draft, and wind does not exceed Po's 2; the clean single ship runs at 12.5 knots in deep and still waters in free trial. Load 6 tons of fuel oil, the main engine can continue working 40 hours under the rated condition. The ship is nearly flat floating and the average draft is 1.7 meters in the state of full-load outbound port. Equipped with two NACA0015 streamline balance rudders and a $2 \times 8 \mathrm{Knm}$ synchronous hydraulic steering gear, the ship is easier to control.

The overall layout is required as follows. (1)Bilges: steering gear room, fuel oil tank $(\mathrm{P} / \mathrm{S})$, engine room, empty cabin, fresh water tank $(\mathrm{P} / \mathrm{S})$, store tank/bow thruster compartment and fore peak are equipped on the demihulls in turn from the tail to the head.(2)Main deck: poop deck, deck room (engine room hatch, galley, toilet, drawing room/dining room, crew room) are equipped in turn from the tail to the head and the head deck area is set as open and high deck. (3) bridge deck: driving console, driving chair, workbench and so on, are set in the pilothouse, people can pass through step stairs which is set in the port side and starboard of FR21.

The hull structure is designed as follows. Structure of the ship was designed on the basis of the relevant requirements of the "domestic sailing ships manufacturing specification" (2015) for coastal sailing areas' catamaran. The two demihulls of catamaran's head(FR44-head), middle(FR24-FR33) and tail(FR8-tail) are connected respectively by closed torsion box, and cross structure with bottom sealing plates are set on other parts. The material of main hull and deck room is CCSA grade steel. The frame spacing is $500 \mathrm{~mm}$, but beam arch is $85 \mathrm{~mm}$. Each demihull is designed as single bottom, single board, full electric welding and transverse frame system. Solid frame plate is set on each position of frame in engine room. The two demihulls are connected with cross-structure decks where torsional box is set.

According to the above design requirements, the overall design of ship is shown in Figure I. The main dimensions of hull are designed as follows: length overall $\left(\mathrm{L}_{\mathrm{OA}}\right) 26.98 \mathrm{~m}$, length on waterline $\left(\mathrm{L}_{\mathrm{WL}}\right) 24.37 \mathrm{~m}$, molded breadth(B) $8.4 \mathrm{~m}$, the width of demihull(b) $2.8 \mathrm{~m}$, total width $\left(\mathrm{B}_{\max }\right) 8.9 \mathrm{~m}$, molded
depth(D) 3.0m, designed $\operatorname{draft}(\mathrm{d}) \quad 1.7 \mathrm{~m}, \quad$ designed $\operatorname{speed}(\mathrm{v}) \sim 12.5 \mathrm{kn}$.

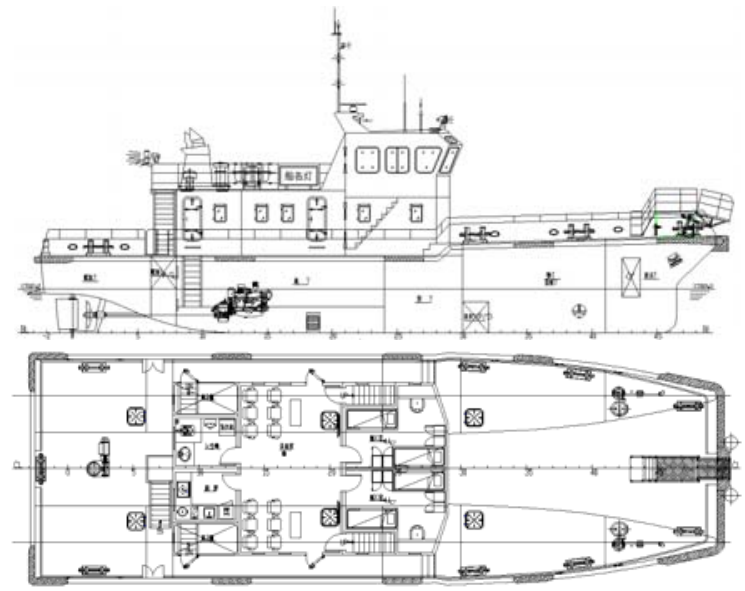

FIGURE I. STRUCTURE OF WHOLE SHIP

\section{ESTABLISHMENT OF THE FINITE ELEMENT MODEL OF} WIND POWER OPERATION AND MAINTENANCE CATAMARAN

Due to the complexity of hull structure, it has some difficulties to establish the whole ship's finite element model. So the actual structure of ship's hull is simplified by using the knowledge of structural mechanics and finite element, and the whole model is concluded by means of selecting and simulating the appropriate types of finite element ${ }^{[7-8]}$.

Coordinate system for the finite element model of the whole ship is that: Coordinate system is established at midlongitudinal section of cross structure, and the origin is located at the midpoint of the baseline at transom plate's connecting line in demihulls. According to the law of right hand, $\mathrm{X}$ axis (longitudinal) points to the captain direction, Y axis (horizontal) to left demihull, $\mathrm{Z}$ axis (vertical) to the cross structure deck.

The structure model of the whole ship's finite element calculation includes main components of ships. Two dimensional and 3 or 4 node shell element simulation were applied on the models deck, broadside plate, bottom deck, hull girder web, bulkhead plate, bridge deck, bridge torsional box bottom, cross structure diaphragm and etc. Others like longitudinal bone, reinforced bar, longitudinal truss plate were simulated by the method of 2 node beam element. Some of structural details that have little effect on the strength of hull were simplified and dealt with necessarily. The total number of nodes in finite element model of demihull and cross structure is 16410 after the discretization of structure. And the number of elements is 24834 . The calculation of wave load seven kinds of working conditions are mainly considered in this paper, including four kinds of working conditions of longitudinal strength (LC1-full load export, LC2-full load import, LC3-no load export, LC4-no load import), total transverse strength (LC5-full load export, wave direction to 90 degrees), torsion strength(LC6-full load export, wave direction to 45 degrees and LC7-full load export, wave direction to 135 degrees).

The model of wave load forecasting consists of two parts: wet surface model and quality model. The former is applied to structural finite element mesh of hull plate, and the latter is 
used to describe quality distribution of the whole ship. In this paper, PATRAN-PRE was used to model the hull shell to generate a hydrodynamic model in order to calculate wave induced loads through the software of SESAM. The number of this model's surface elements (Panel) is 3394. The horizontal beam element was used to simulate quality distribution along the direction of ship' length, and quality model of various loading conditions was established by using the data of empty ship's weight distribution and the loading manual.

\section{A. Determination of Design Wave Parameters}

The template is designed so that author affiliations are not repeated each time for multiple authors of the same affiliation. Please keep your affiliations as succinct as possible (for example, do not differentiate among departments of the same organization). This template was designed for two affiliations.

\section{B. Transfer Function}

According to the "domestic sailing ships manufacturing specification" (2015) 1.9.7.2, wave load are determined by the method of equivalent design wave and comply with the following requirements: (1) Ship motion and wave load are calculated based on two dimensional linear slice theory, three dimensional linear theory (considering the nonlinear correction) or nonlinear wave theory. (2) the requirements of input parameters when ship motion and wave load are calculated under the condition of design wave are as following: (a) The number of wave frequency (wavelength) is not less than 20, and the wave frequency range should be selected in accordance with the ratio range's $0.2 \sim 3$ of wavelength to the length of ship $(\lambda / L)$. The step size is 0.1 . (b) No less than 7 wave directions are selected, including 0 degrees(face to wave), 30 degrees, 60 degrees, 90 degrees, 120 degrees, 150 degrees and 180 degrees(along wave). (c) The calculation speed is zero. The transfer function of vertical wave bending moment and wave shear in different wave directions is calculated by HydroD (WADAM), which is a programming module of three dimensional wave load in SESAM.

\section{The wave Induced Loads}

Wave induced loads are predicted by statistical analysis technique. In the long term of the forecast calculation, wave diagram is used to indicate the environmental conditions of a sea area. And the different sea conditions and probability of occurrence of each sea condition can also be represented by this diagram. At present, many wave diagrams of different sea conditions have been written. There is one third merchant shipping and more detailed study on the North Atlantic route with intense trade competition. Therefore, in this paper, the North Atlantic's wave diagram is served as a referenced sea condition in long-term forecast.

In this paper, long-period forecast for the ship is determined according to wave scatter diagram of the DNV North Atlantic: the transfer function of ship motion and ship wave induced load are calculated with three dimensional surface element theories; scatter diagram is simulated by wave spectrum named Pierson-Moscowitz, and the extended distribution is fit by using two dimensional weibull distribution. By using the Postresp module of SESAM, the long-term prediction results of wave loads under different load conditions are calculated.

\section{Design wave Method}

After getting the results of long-term forecast, it is necessary to consider all influential factors and combine them correctly, so as to get the calculated load. In projects, design wave method is usually selected to determine parameters of design wave. The wave direction and frequency are designed by frequency response function curves which indicate the main load parameters' frequency under the situation of different course angles of the regular waves. The wave amplitude of equivalent design wave is determined by the extended extreme value of the load parameters 'prediction and the value of frequency response function, and it is calculated by formula (1):

$$
a_{w}=\frac{L_{j}}{A_{j}}
$$

In the equation, $a_{w}$-amplitude of design wave, $\mathrm{m} ; L_{j}-$ permanent forecast value of main load parameters, probability level is $10^{-8} ; A_{j}$ - extreme value of the main load parameters; $j$ - the number of the main load control parameters, for example: $j=1$ represents the vertical wave bending moment.

The length of equivalent design wave is determined by frequency corresponding to the extreme value of the frequency response function, and it is calculated by formula (2):

$$
\lambda=(2 \pi g) / \omega_{a}
$$

In the equation, $\lambda$-length of design wave, $\mathrm{m} ; g$ acceleration of gravity; $\omega_{a}$ - wave frequency corresponding to the extreme value of the main load parameters, $\mathrm{rad} / \mathrm{s}$.

According to the specification, the equivalent parameters of design wave under each working condition are shown in Table I.

\begin{tabular}{|c|c|c|c|c|c|}
\hline $\begin{array}{c}\text { Load } \\
\text { Conditio } \\
\mathbf{n}\end{array}$ & $\begin{array}{c}\text { Frequenc } \\
\text { y (rad/s) }\end{array}$ & $\begin{array}{l}\text { Wave } \\
\text { Lengt } \\
\text { h (m) }\end{array}$ & $\begin{array}{c}\text { Wave } \\
\text { Directio } \\
n\left({ }^{\circ}\right)\end{array}$ & $\begin{array}{c}\text { Phase } \\
\text { Position( }{ }^{\circ} \\
\text { ) }\end{array}$ & $\begin{array}{c}\text { Wave } \\
\text { Amplitude( } \\
\text { m) }\end{array}$ \\
\hline LC1 & 2 & 15.409 & 150 & 29.653 & 2.181 \\
\hline $\mathrm{LC} 2$ & 2 & 15.409 & 30 & 54.334 & 2.193 \\
\hline $\mathrm{LC} 3$ & 2 & 15.409 & 150 & 29.950 & 2.168 \\
\hline $\mathrm{LC} 4$ & 2 & 15.409 & 30 & 54.524 & 2.180 \\
\hline LC5 & 1.9 & 17.074 & 90 & -63.376 & 1.007 \\
\hline LC6 & 1.8 & 19.024 & 45 & 39.567 & 2.409 \\
\hline LC7 & 1.8 & 19.024 & 135 & -149.804 & 2.458 \\
\hline
\end{tabular}

TABLE I. PARAMETERS OF DESIGN WAVE

\section{E. Calculation of Wave Pressure}

The moment of main load parameter reaching the extreme value is determined by the phase position corresponding to the extreme value of the frequency response function, which can be calculated by the following formula:

$$
t_{j}=\left(n \pi+\pi / 2-\varepsilon_{j}\right) / \omega_{a}
$$

In the equation, $\omega_{a}$-wave frequency corresponding to the extreme value of main load parameters, $\mathrm{rad} / \mathrm{s} ; \varepsilon_{j}$ - the phase angle corresponding to the extreme value of main load 
parameters, rad; $n-0$ or 1 , select anyone according to sagging or hogging of the wave vertical bending moment.

According to the equivalent parameters of design wave in Table 1, the unit load of wave amplitude (wave pressure) is calculated under the four kinds of working conditions of total longitudinal strength.

The spatial rigid body movement of the whole ship model is limited by 6 displacement components, and there is no effect for relative deformation of each part of hull. Considering all kinds of working conditions and adding other loads: (1)weight of crew and baggage; (2) outboard hydrostatic pressure; (3) pressure of ballast water, fuel oil and other liquid. The results of wave pressure and hydrostatic pressure are added to wet surface model by using PLC language, and then the load of wet surface model is mapped to the finite element model of structure.

\section{F. Horizontal Split Force and Anti-symmetric Vertical Uniform force}

1) Horizontal split force: A larger transverse bending moment will be produced on cross structure when catamaran bears the transverse bending load with lateral wave coming. The total transverse bending moment of cross structure is equivalent to the lateral force imposed on a node of the midlongitudinal section lines along the transverse strong frames (including transverse bulkhead) of demihulls.

The lateral force can be calculated by the following formula.

$$
f_{y}=\frac{M_{b x}}{n z}
$$

In the formula, $M_{b x}$ - total transverse bending moment of cross structure, determined by the design wave method. $M_{b x}=7.221 \times 10^{5} N \cdot m$, known from the long term forecast value calculated in the section of $3.2 ; z$-vertical distance between the point of lateral force application and the neutral axis of cross structure's mid-longitudinal section. The lateral force application point is the bottom node of strong frames at baseline of demihull's mid-longitudinal section, and the vertical position of neutral axis of cross structure's midlongitudinal section is $\mathrm{z}=3 \mathrm{~m}$. $\mathrm{n}$ - the total number of strong frames with lateral force application and transverse bulkheads. In this model, there're 14 strong frames and 6 transverse bulkheads. So $\mathrm{n}=20$.

2) Anti-symmetric vertical uniform force: nephograms When the wave is oblique, longitudinal motion out of sync will be happened in two demifulls of catamaran, resulting to torsional deformation. The total transverse torque of catamaran is equivalent to the anti-symmetric vertical uniform force application in the mid-longitudinal section of demihulls. In other words, the vertical uniform equivalent force is antisymmetric about the mid-longitudinal section and the midship section of catamaran.

Equivalent vertical distribution load is calculated by the following formula:

$$
p_{x}=\frac{2 M_{t y}}{n L}
$$

In the formula, $M_{t y}$ — torque of cross structure, $L-$ length of catamaran, $n$ - the number of additional nodes in mid-front part or mid-rear part, the mid-rear part $n=42$, the mid-front part $\mathrm{n}=52$. According to the long term forecast values calculated in the section of $3.2, M_{b x}=1.674 \times 10^{6} \mathrm{~N}$. $m$, when wave direction is $45^{\circ} ; M_{b x}=1.679 \times 10^{6} \mathrm{~N}$. $m$,when wave direction is $135^{\circ}$.

\section{Strength Assessment of the Whole ShiP}

According to the "domestic sailing ships manufacturing specification"(2015) Section 9 Chapter 1 Article 2, "direct calculation of structural strength" and Appendix 1 "direct calculation of catamaran structural strength" in Chapter 19 "catamaran", the allowable stress of common marine steel structure(CCSA) is chosen as $200 \mathrm{~N} / \mathrm{mm}^{2}$ of equivalent stress and $90 \mathrm{~N} / \mathrm{mm}^{2}$ of shear stress.

The whole ship is divided into left demihull, right demihull and cross structure, in order to assess the stress. Equivalent stress and shear stress of the deck, hull plate, longitudinal hull components, transverse bulkhead and horizontal frame in the left or right demihulls are calculated. But for the cross structure, the bridge deck, the bottom plate of cross structure's torsional box, longitudinal and transverse components of bridge are calculated. The deformation nephogram of the whole ship under different conditions is shown in Figure II.

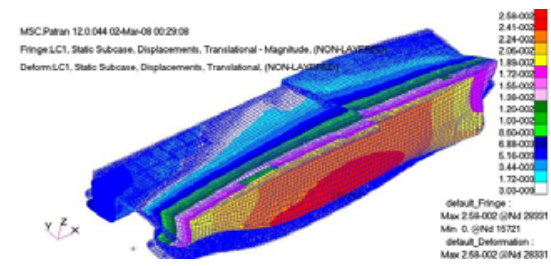

$\mathrm{LC} 1$

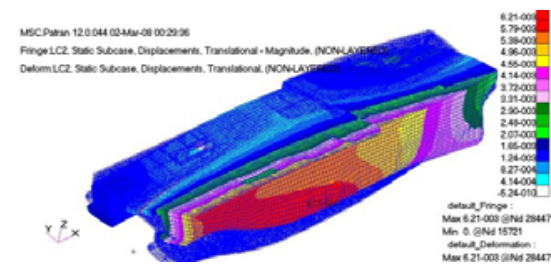

LC2

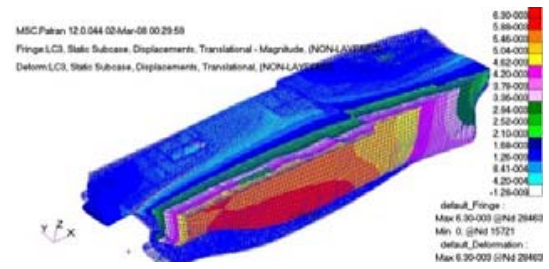

LC3 


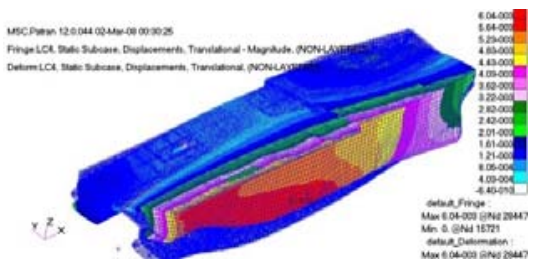

$\mathrm{LC} 4$

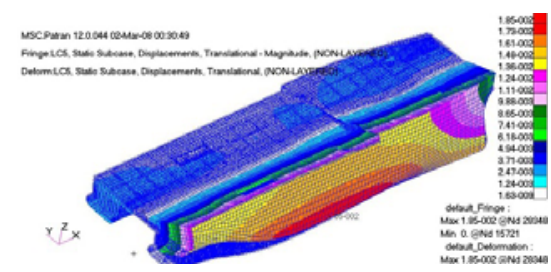

LC5

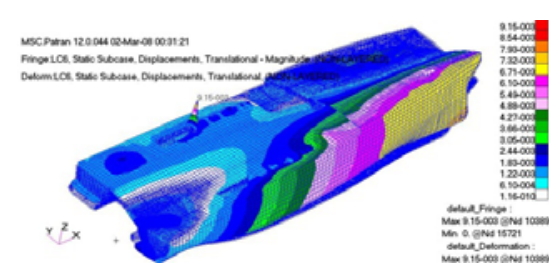

LC6

FIGURE II. DEFORMATION NEPHOGRAM OF WHOLE SHIP

\section{RESULTS OF ASSESSMENTS AND RECOMMENDATIONS}

According to the check results of primary members, left demihull, right demihull and cross structure, the structural strength of 24m's operation and maintenance catamaran satisfy the relevant requirements in the "domestic sailing ships manufacturing specification"(2015) Section 9 Chapter 1 Article 2 "direct calculation of structural strength" and Appendix 1 "direct calculation of catamaran structural strength" in Chapter 19 "catamaran".

The ship's decks and bottom plate are checked for allowable buckling strength with the method of buckling strength written in the "domestic sailing ships manufacturing specification". And the results indicate that the buckling strength meet the specifications.

By the results of calculation, it can be seen that primary members of wind power operation and maintenance catamaran can meet the requirements of buckling strength, but some high stress is still appeared in local areas, such as mid-longitudinal section line of deck opening edge, area near the intersection of transverse bulkhead and transverse diaphragm of bridge, the intersection of tail diaphragm on the mid-longitudinal section and bridge girder and so on. Not exceeding the allowable stress, so the local area can be reinforced by increasing the profile and aggregate. Cross structure and transverse bulkhead are the main loaded components under the action of transverse bending moment. Considering the serious stress concentration in cross structure and interface position, more attention should be paid to the structure and connection mode of that. With the torsional loaded, torsional moment is the greatest risk for catamaran because of the serious stress concentration on both ends of the cross structure. And consequently, in the process of design for catamaran's hull, it is necessary to take some intensified measures to strengthen the torsional strength of cross structure appropriately.

\section{CONCLUSIONS}

The structural strength assessment of offshore wind power operation and maintenance catamaran is one of the important contents to ensure the safety of structure. A wind power operation and maintenance catamaran is shown as an example in this paper, which is divided into 7 working conditions when at outbound or inbound port, full or no load and different wave directions, through finite element modeling of the ship and reasonable determinations of calculated conditions and loads. According to relevant requirements of the "domestic sailing ships manufacturing specification", the structure strength of catamaran is checked and the calculation results indicate that the structure should be strengthened. What's more, some important references for structure design and strength assessment of the same type of wind power operation and maintenance ship are also provided by these results.

\section{REFERENCES}

[1] XIE Yunping, ZHANG Yutang, KONG Xiangming. Strength Analysis of the Connector of Offshore Wind-farm Maintenance Ship [J]. Ship \& Ocean Engineering, 2015,01:158-161+165.

[2] ZHANG Xiuping. The Ship Form and Related Performance Research of Maintenance Catamaran in Offshore Wind Farms [D] Jiangsu University of Science and Technology,2014.1-10.

[3] WEI Li. Research of Structure Design and Strength Analysis for Highspeed Catamaran in Offshore Wind-farm Maintenance [D]. Jiangsu University of Science and Technology, 2014.1-11.

[4] YAO Zhuangle. The Research and Application on Multidisciplinary Design Optimization for Wind Farm Support Vessel [D]. South China University of Technology, 2015. 1-15.

[5] YANG Lingyu, CHEN Yue. The Research and Optimization on Demihulls Spacing of Wind Power Operation and Maintenance Catamaran Based on CFD [J]. Jiangsu Ship, 2015, 06:14-16.

[6] HUANG Linlin, CAO Jialin, ZHANG Kaihua et al. Status and Prospects on Operation and Maintenance of Offshore Wind Turbines [J]. Proceedings of the Chinese Society for Electrical Engineering, 2016, 03:729-738.

[7] Dalgic Y, Lazakis I, Dinwoodie I, et al. Advanced Logistics Planning for Offshore Wind Farm Operation and Maintenance Activities [J]. Ocean Engineering, 2015, 101: 211-226.

[8] Stålhane M, Hvattum L M, Skaar V. Optimization of Routing and Scheduling of Vessels to Perform Maintenance at Offshore Wind Farms[J]. Energy Procedia, 2015, 80: 92-99. 